\title{
Room temperature ferromagnetism promoted by defects at zinc sites in $\mathrm{Mn}$-doped $\mathrm{ZnO}$
}

\author{
V.M. de Almeida ${ }^{\text {a }}$, A. Mesquita ${ }^{\text {b }}$, A.O. de Zevallos ${ }^{\text {c }}$, N.C. Mamani ${ }^{\text {c }}$, P.P. Neves ${ }^{\text {c }}$, \\ X. Gratens ${ }^{d}$, V.A. Chitta ${ }^{d}$, W.B. Ferraz ${ }^{\text {e, }}$ A.C. Doriguetto ${ }^{\text {c }}$, A.C.S. Sabioni ${ }^{a}$, \\ H.B. de Carvalho ${ }^{\text {c, * }}$ \\ ${ }^{a}$ Universidade Federal de Ouro Preto, Ouro Preto, MG, Brazil \\ b Departamento de Física, Instituto de Geociências e Ciências Exatas, Universidade Estadual Paulista, 13500-970 Rio Claro, SP, Brazil \\ ' Universidade Federal de Alfenas, 37130-000 Alfenas, MG, Brazil \\ ${ }^{\mathrm{d}}$ Instituto de Física da Universidade de São Paulo, São Paulo, SP, Brazil \\ e Centro de Desenvolvimento de Tecnologia Nuclear/CNEN, Belo Horizonte, MG, Brazil
}

\section{A R T I C L E I N F O}

\section{Article history:}

Received 1 April 2015

Received in revised form

4 September 2015

Accepted 10 September 2015

Available online 25 September 2015

\section{Keywords:}

Dilute magnetic oxides

Mn-doped $\mathrm{ZnO}$

Defect related magnetism

Structural and magnetic characterization

\begin{abstract}
A B S T R A C T
The nature of the room temperature ferromagnetism in dilute magnetic oxides is still a matter of debate. However, there is a consensus that structural point defects play an important role to achieve a desired long range ferromagnetic order. In this report we have clearly established a correlation between an observed room temperature ferromagnetism and defects at zinc sites for $\mathrm{Mn}$-doped $\mathrm{ZnO}\left(\mathrm{Zn}_{0.93} \mathrm{Mn}_{0.03} \mathrm{O}\right)$ samples prepared by the solid state reaction method and subject to post-annealing under reducing atmosphere. Detailed microstructural analysis was carried out to exclude the presence of extrinsic sources of ferromagnetism. Photoluminescence and Hall measurements reveal that the main present defects in the samples are associated to defects at the zinc sites. Magnetic characterization demonstrates a room temperature ferromagnetic behavior associated to a paramagnetic Curie-Weiss component. The magnetization and density of defects expressively reduces after the post-annealing. In this context, the defect mediated magnetic coupling between Mn atoms under the scope of the bound magnetic polaron model and the $d^{0}$ ferromagnetism are used to interpret the magnetic properties.
\end{abstract}

(c) 2015 Elsevier B.V. All rights reserved.

\section{Introduction}

Currently, there is an intense interest in the search for ferromagnetic order in semiconductor materials doped with small amounts of transition metal (TM), the so called diluted magnetic semiconductors (DMS). Such kind of materials can, potentially, be used in the development of spintronic devices, a new technology based on the spin degree of freedom of the charge carriers [1]. The room temperature ferromagnetism (RTFM) in Mn-doped wideband-gap semiconductors, specifically $\mathrm{ZnO}$ and $\mathrm{GaN}$, was theoretically predicted by Dietl et al. [2]. Following their report a huge effort has been concentrated on TM-doped oxide semiconductors studies [3]. Concerning the Mn-doped $\mathrm{ZnO}$ system, the first observation of RTFM was performed by Sharma et al. [4]. However, their results were quickly challenged by Kundaliya et al. [5], who

\footnotetext{
* Corresponding author.

E-mail address: bonette@unifal-mg.edu.br (H.B. de Carvalho).
}

claimed that the observed RTFM was due to a secondary phase, $\mathrm{Mn}_{2-x} \mathrm{Zn}_{x} \mathrm{O}_{3-\delta}$. In fact, in spite of extensive investigations, the origin of the observed RTFM remains inconclusive and controversial. Up to now, the consensus is that defects play an important role to drive the ferromagnetic behavior [6,7], what could explain the disparity among experimental reports and the attested high sensibility to the preparation conditions observed for the TM-doped oxides. In this scenario, one of the most important theoretical models is the static magnetic polaron theory proposed by Coey et al. [8]. Here, a spatial overlap between localized electrons trapped by shallow donor defects and the magnetic doped atoms leads to a ferromagnetic exchange coupling between them, forming a bound magnetic polaron (BMP). Nevertheless, the nature of the specific point defect necessary to form the BMP is also a matter of debate. On the literature one can find several experimental reports arguing that the observed RTFM, explained in terms of the BMP model, is associated to oxygen vacancies $\left(V_{O}\right)[9,10]$, on the contrary, zinc interstitials $\left(Z n_{\mathrm{i}}\right)$ and zinc vacancies $\left(V_{\mathrm{Zn}}\right)$ have been cited 
very often [11-14]. Considering also the reported RTFM for undoped systems, another important theoretical model is the $d^{0}$ ferromagnetism, where point defects are the responsible ones for the RTFM by means of a spin polarized density of states around the Fermi level [15]. Even in the BMP or in the $d^{0}$ ferromagnetism model, it is important to stress that the defect concentration plays a fundamental role to achieve the RTFM.

In the present work we report a detailed study of the microstructure and the magnetic properties of $\mathrm{Zn}_{1-x} \mathrm{Mn}_{x} \mathrm{O}$ bulk samples with Mn molar concentrations of 3 at.\% prepared by the standard solid-state reaction method. The samples were prepared under oxygen atmosphere, after all, fraction of the samples were subjected to a thermal treatment process in order to change the densities of pre-existent defects. The structural results indicated the substitutional character of the $\mathrm{Mn}$ ions on the $\mathrm{Zn}$ sites of the $\mathrm{ZnO}$ wurtzite structure without any evidence of secondary phases. Magnetic results demonstrated a coexistence of paramagnetic and a ferromagnetic phase for both samples at room temperature. The experimental results obtained from both structural and magnetic characterization allowed us to associate the observed RTFM to defects at $\mathrm{Zn}$ sites $\left(Z n_{\mathrm{i}}\right.$ and $\left.V_{\mathrm{Zn}}\right)$.

\section{Experimental}

Polycrystalline $\mathrm{Zn}_{0.97} \mathrm{Mn}_{0.03} \mathrm{O}$ samples were prepared by the standard solid state reaction method. Stoichiometric amounts of $\mathrm{MnO}$ (Alfa Aesar 99.99\% purity) and ZnO (Alfa Aesar 99.999\% purity) powders were mixed and ball milled for $5 \mathrm{~h}$ using $\mathrm{Zn}$ spheres. The resulting powder was cold compacted under pressure of $600 \mathrm{MPa}$ in the form of pellets (green pellets). The green pellets were finally sintered in oxygen atmosphere at $1400{ }^{\circ} \mathrm{C}$ for $4 \mathrm{~h}$. Fraction of these samples were then post-annealed in a $\mathrm{Ar}(95 \%)$ and $\mathrm{H}_{2}(5 \%)$ atmosphere at $600{ }^{\circ} \mathrm{C}$ for $3 \mathrm{~h}$. Throughout the article the as prepared sample will be labeled $\mathrm{ZM} 3-\mathrm{O}_{2}$ and the post-annealed sample ZM3$\mathrm{ArH}_{2}$. The thermal treatment is not in order to introduce hydrogen specimens in the sample. As shown by S. G. Koch et al. thermal treatments below $800{ }^{\circ} \mathrm{C}$, even under high pure hydrogen gas pressure, is not sufficient to perform a hydrogenation process [16]. The structural characterization and the effects of thermal treatment were investigated by Powder X-ray diffraction (XRD) using a Rigaku Ultima IV equipment employing $\mathrm{Cu} \mathrm{K} \alpha$ radiation $(30 \mathrm{kV}, 40 \mathrm{~mA}$, $\lambda=1.5405 \AA$ ) recorded in the range of $2 \theta=30-70^{\circ}$ with steps of $0.01^{\circ}$ at $5 \mathrm{~s} / \mathrm{step}$. The determination of the lattice parameters and the occupation factor over the structure were performed by using the Rietveld method as implemented by the General Structure Analysis System (GSAS) software package with the graphical user interface EXPGUI [17,18]. The microstructure and the composition distribution were characterized by scanning electron microscopy (SEM) and energy dispersive X-ray spectrometry (EDS) by means of a SEM-LV JEOL JSM 5900. Raman spectroscopy was used to study the $\mathrm{Mn}$ incorporation into the $\mathrm{ZnO}$ matrix and the resulting lattice disorder, as well as to analyze the formation of segregated secondary phases. Raman was carried out at room temperature using a Jobin-Yvon-64000 system in the backscattering geometry using the $532 \mathrm{~nm}$ line of a solid-state laser for excitation. X-ray absorption near-edge structure (XANES) and extended X-ray absorption fine structure (EXAFS) was used to determine the valence state of the $\mathrm{Mn}$ dopant and to evaluate the environment of $\mathrm{Mn}$ in the $\mathrm{ZnO}$ lattice. The X-ray absorption measurements were performed at Mn and $\mathrm{Zn} K$-edge in the transmittance mode at the XAS beamline from the Brazilian Synchrotron Light Laboratory (LNLS), Campinas, Brazil. The extraction, normalization, and fitting of the spectra were performed using the Multiplatform Applications for XAFS (MAX) software package, and theoretical spectra were calculated using the FEFF9 code $[19,20]$. The structural defects and their relative concentrations was determined by photoluminescence (PL) and Hall effect. The magnetic measurements were performed using a superconducting quantum interference device magnetometer (SQUID).

\section{Results and discussion}

\subsection{X-ray diffraction}

Fig. 1 shows the X-ray diffraction (XRD) results for our $\mathrm{Zn}_{0.97} \mathrm{Mn}_{0.03} \mathrm{O}$ samples. The refined Rietveld XRD patterns and residual difference between experimental and fitted patterns are also presented. All observed peaks correspond to those expected for polycrystalline wurtzite $\mathrm{ZnO}$. We observe that the peaks present relative narrow line-widths revealing a good crystallinity. The Rietveld refinement initiated with $\mathrm{Zn}^{2+}$ and $\mathrm{O}^{2-}$ atoms located at $(1 / 3,2 / 3,0)$ and $(1 / 3,2 / 3, z)$, respectively. The fitted curves match quite well with the experimental data. Table 1 presents the Rietveld statistics and the determined cell parameters. The two samples present cell dimensions a little bit higher than those reported for pure $\mathrm{ZnO}$ [21]. The observed increase was expected considering that the $\mathrm{Mn}^{2+}$ ions (tetrahedral ionic radius $=0.66 \AA$ ) replace the $\mathrm{Zn}^{2+}$ ions (tetrahedral ionic radius $=0.60 \AA$ ) in the wurtzite matrix $[22,23]$. Therefore, the XRD results indicate that the Mn ions in our samples are taking the place of $\mathrm{Zn}$ in the $\mathrm{ZnO}$ wurtzite structure. We also observe no significant change in the wurtzite cell lattice parameters with the annealing process.

Another important result of Rietveld refinement is the elemental occupation factors, which can give us an estimative of the concentration of defects associated to vacancies and the Mn concentration in the samples. The obtained elemental occupation factors are presented in Table 2 . The Mn concentration found for the two samples are in good agreement to the nominal doping value (3\%). However, we observed significant differences comparing the occupation factors for the cationic ( $\mathrm{Zn}$ and $\mathrm{Mn}$ ) sites of $\mathrm{ZM} 3-\mathrm{O}_{2}$ and $\mathrm{ZM} 3-\mathrm{ArH}_{2}$ samples. This data indicates cationic vacancies $\left(V_{\mathrm{Zn}} \sim 2\right.$ at.\%) for $\mathrm{ZM} 3-\mathrm{O}_{2}$ sample. On the other hand, oxygen vacancies are not observed for $\mathrm{ZM} 3-\mathrm{O}_{2}$. These results suggest a partial migration of transition metal atoms to interstitial sites in the wurtzite structure of $\mathrm{ZM} 3-\mathrm{O}_{2}$ in order to guaranty the cationic/ anionic neutrality of bulk material. That means, XRD results suggest

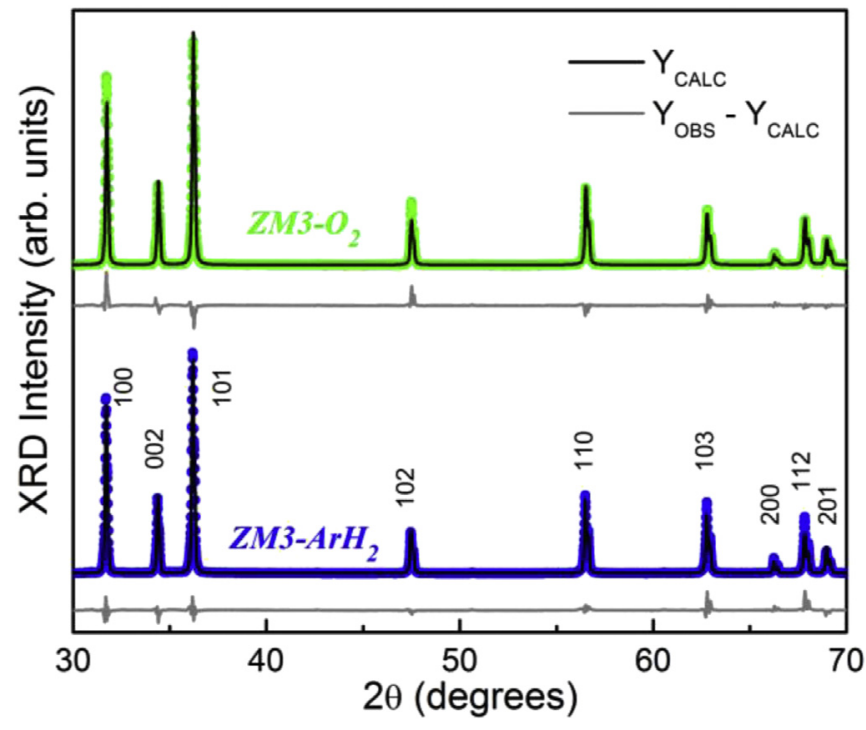

Fig. 1. Refined XRD diffractograms of polycrystalline $\mathrm{Zn}_{0.97} \mathrm{Mn}_{0.03} \mathrm{O}$ samples. Each figure shows the observed pattern (symbols), Rietveld calculated pattern (solid line), and goodness of fit or residual pattern (at the bottom). 
Table 1

Structural data for the $\mathrm{Zn}_{0.97} \mathrm{Mn}_{0.03} \mathrm{O}$ samples obtained through the Rietveld refinement. $\chi^{2}$ is the square of goodness-of-fit indicator, and $R_{\mathrm{Bragg}}$ is the refinement quality parameter.

\begin{tabular}{lllllr}
\hline Sample & $a(\AA)$ & $c(\AA)$ & Volume $\left(\AA^{3}\right)$ & $\chi^{2}$ & $R_{\text {Bragg }}$ \\
\hline ZM3-O $_{2}$ & $3.2549(1)$ & $5.2116(2)$ & $47.816(6)$ & 8.27 & 9.83 \\
ZM3-ArH $_{2}$ & $3.2550(1)$ & $5.2116(3)$ & $47.820(5)$ & 3.24 & 10.55 \\
\hline
\end{tabular}

Table 2

Elemental occupation factor for the $\mathrm{Zn}_{0.97} \mathrm{Mn}_{0.03} \mathrm{O}$ samples obtained through the Rietveld refinement.

\begin{tabular}{lllll}
\hline Sample & $\mathrm{Zn}$ & $\mathrm{Mn}$ & $\mathrm{Zn}+\mathrm{Mn}$ & $\mathrm{O}$ \\
\hline $\mathrm{ZM}_{3}-\mathrm{O}_{2}$ & $0.956(1)$ & $0.025(1)$ & $0.981(2)$ & $1.012(5)$ \\
$\mathrm{ZM}-\mathrm{ArH}_{2}$ & $0.976(1)$ & $0.030(1)$ & $1.006(2)$ & $1.013(4)$ \\
\hline
\end{tabular}

the presence of zinc interstitials $\left(\mathrm{Zn}_{\mathrm{i}}\right)$ sites in $\mathrm{ZM} 3-\mathrm{O}_{2}$ beyond the wurtzite crystallographic ones. For $\mathrm{ZM} 3-\mathrm{ArH}_{2}$ neither cationic nor oxygen vacancies are observed. These data was further confirmed by analyses of the PL and Hall results.

\subsection{Electron microscopy and elemental analyses}

Fig. 2(a) and (b) show representative scanning electron microscope (SEM) images for the $\mathrm{ZM} 3-\mathrm{O}_{2}$ and the $\mathrm{ZM} 3-\mathrm{ArH}_{2}$ samples, respectively. The images were acquired using a backscattered electron detector (BSE) of a SEM-LV JEOL JSM 5900 that has a resolution down to $3 \mathrm{~nm}$ at $30 \mathrm{kV}$. A series of full scans over large areas show no evidence of crystallographic secondary phase or local segregation of Mn ions (Mn-rich clusters), strongly suggesting that the studied samples are in diluted state with the Mn ions assuming the $\mathrm{Zn}$ sites into the $\mathrm{ZnO}$ wurtzite structure. The effective $\mathrm{Mn}$ concentrations $\left(x_{\mathrm{EE}}\right)$ of the $\mathrm{Zn}_{0.97} \mathrm{Mn}_{0.03} \mathrm{O}$ samples were also measured by energy dispersive X-ray spectrometer (EDS). The EDS analyses were performed in multiple points and also over large

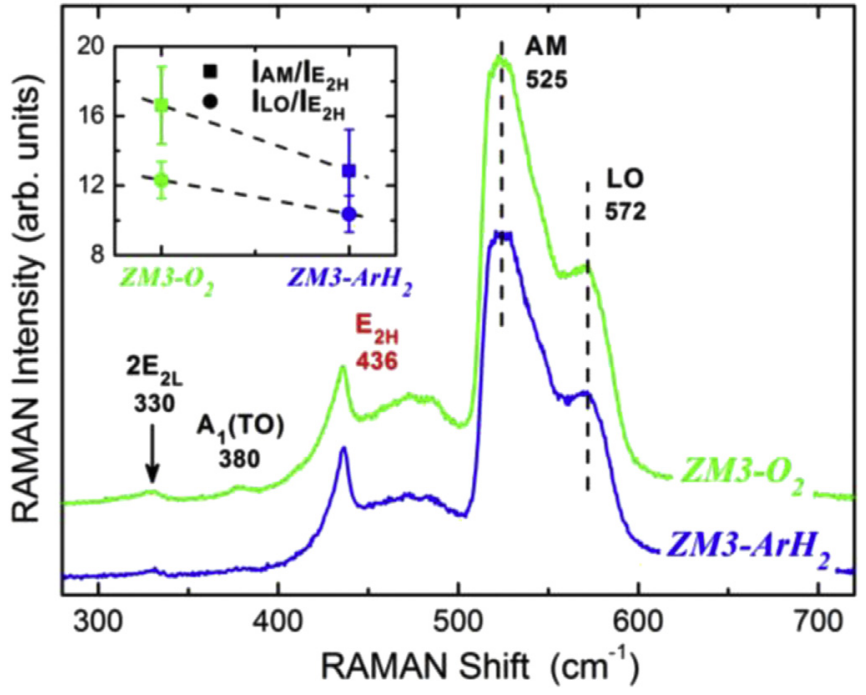

Fig. 3. Raman scattering spectra of the polycrystalline $\mathrm{Zn}_{0.97} \mathrm{Mn}_{0.03} \mathrm{O}$ samples. The spectra were acquired at room temperature and are normalized by the main vibrational mode $E_{2 \mathrm{H}}$. The inset presents the intensity of the AM and LO modes relative to the $E_{2 \mathrm{H}}$. The intensities were obtained from multipeak Lorentz fittings.

areas. Representative EDS spectrum for our $\mathrm{Zn}_{0.97} \mathrm{Mn}_{0.03} \mathrm{O}$ samples are presented in Fig. 2(c) and (d). The average measured effective Mn concentration $\left(x_{\mathrm{EE}}\right)$ was $0.028 \pm 0.006$ for sample $\mathrm{ZM} 3-\mathrm{O}_{2}$ and $0.031 \pm 0.002$ for sample $\mathrm{ZM} 3-\mathrm{ArH}_{2}$ (these data are also presented in Table 6). These results are in good agreement with the nominal concentration and the values obtained by Rietveld refinement.

\subsection{Raman scattering spectroscopy}

Raman spectra from our $\mathrm{Zn}_{0.97} \mathrm{Mn}_{0.03} \mathrm{O}$ samples are shown in
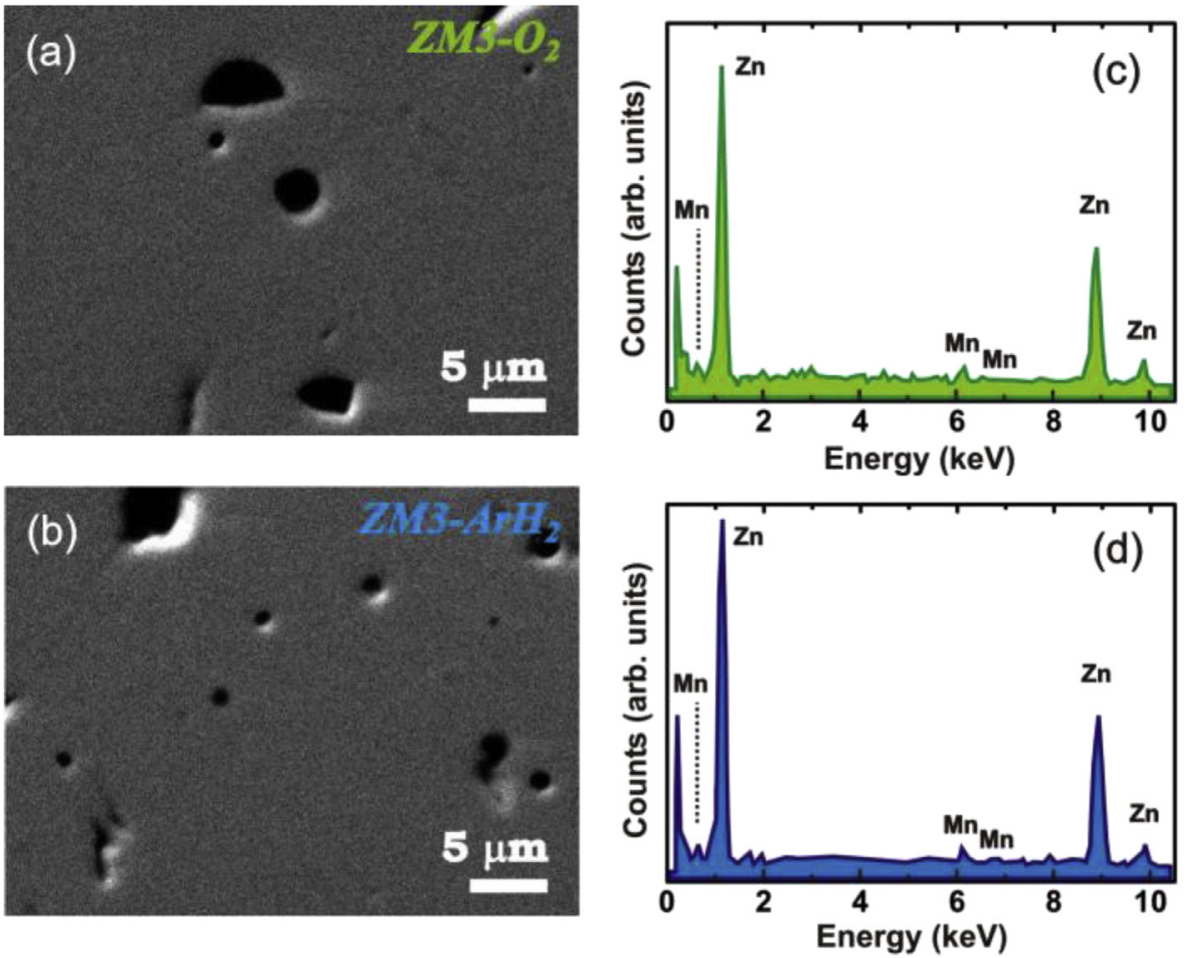

Fig. 2. Representative scanning electron micrographs, (a) and (b); and EDS spectrum, (c) and (d), for the $\mathrm{ZM}_{3}-\mathrm{O}_{2}$ and the $\mathrm{ZM} 3-\mathrm{ArH}_{2}$ samples, respectively. 
Fig. 3. The spectra were normalized by the main vibrational mode $E_{2 \mathrm{H}}$. The frequencies of the allowed vibrational modes for the $\mathrm{ZnO}$ wurtzite structure, $A_{1}, E_{1}$ and $E_{2}$, are well established in the literature [24,25]. Here the $A_{1}$ and $E_{1}$ are optical phonon modes (transversal (TO) and longitudinal (LO)) and the $\mathrm{E}_{2}$ is a non-polar mode. We observe a series of narrow modes centered at 330, 380 and $436 \mathrm{~cm}^{-1}$, that are assigned to the $2 E_{2 \mathrm{~L}}, A_{1}(\mathrm{TO})$ and $E_{2 \mathrm{H}} \mathrm{ZnO}$ modes, respectively. All these modes are observed for both studied samples. A significant result from the Raman data is the complete absence of modes related to segregated secondary phases. The Raman scattering results together with the XRD data and the SEM/ EDS analysis, are strong evidences that $\mathrm{Mn}$ ions in our samples are incorporated into the $\mathrm{ZnO}$ matrix.

In Fig. 3 we also observe a broad band between 500 and $600 \mathrm{~cm}^{-1}$. This broad band seems to enclose several modes, whereas the main ones are centered at 525 and $572 \mathrm{~cm}^{-1}$. The peak at $572 \mathrm{~cm}^{-1}$ can be attributed to the overlap of the LO phonons of the $A_{1}$ and $E_{1}$ modes [24], but the peak at $525 \mathrm{~cm}^{-1}$ cannot be attributed to a pure-ZnO vibrational mode; it is indexed as an additional mode (AM) in Fig. 3 . In pure $\mathrm{ZnO}$, the $A_{1}(\mathrm{LO})$ and $E_{1}(\mathrm{LO})$ modes are usually very weak due to the destructive interference between the deformation and the Frölich potentials [26], however the crystalline disorder induced by the incorporation of dopant, impurities and defects can also explain the emergence of the broad band. Similar results are observed in different systems involving intrinsic point defects [27]. In our samples, the incorporation of the $\mathrm{Mn}$ ions in the $\mathrm{ZnO}$ wurtzite structure would also introduce disorder in the system, given the already mentioned differences between the ionic radius of the $\mathrm{Mn}^{2+}$ and $\mathrm{Zn}^{2+}$ ions. These distortions may explain the observation of the AM and the LO modes. The inset of Fig. 3 shows the relative intensity of AM and LO modes with respect to the $E_{2 \mathrm{H}}$ mode for the studied samples. We observed that the AM and $\mathrm{LO}$ modes for the $\mathrm{ZM} 3-\mathrm{O}_{2}$ sample has a higher relative intensity than the modes for the $\mathrm{ZM} 3-\mathrm{ArH}_{2}$ sample. As these modes are associated with intrinsic defects, we can state that the as prepared sample has a higher density of defects than the annealed sample. Since the $\mathrm{ZM} 3-\mathrm{O}_{2}$ sample has a higher concentration of cationic vacancies $\left(V_{\mathrm{Zn}}\right)$, determined by the Rietveld refinement for the elemental occupation factors, we can infer that these modes are associated with defects at the $\mathrm{Zn}$ sites.

\subsection{X-ray absorption}

In the energy range of a XANES spectrum the wavelength of the photoelectron is of the order of the interatomic distances and its free path is long enough to allow multiple scattering over the neighboring atoms. The binding energy of the bound electrons rise as the valence increases, thus the energy of the absorption edge shifts according to the valence of the absorbing ion. Therefore, a XANES spectrum involves transitions to free energy levels and multiple scattering processes, carrying information about the density of states, the valence, and the crystallographic environment of absorbing ions. Fig. 4(a) presents the obtained XANES spectra at room temperature for our $\mathrm{Zn}_{0.97} \mathrm{Mn}_{0.03} \mathrm{O}$ samples. First of all, we observe that the obtained spectra for both samples exhibit similar $\mathrm{K}$-edge white line shapes to those previously reported for tetrahedral coordinated TM-doped $\mathrm{ZnO}$ [28]. The similarities between the spectra for our samples indicate also that there are no significant structural changes in the $\mathrm{ZnO}$ wurtzite structure due to the annealing. The valence of the dopant ions can be analyzed by comparing their resulting edge structure to those obtained from reference samples. In Fig. 4(a) we also present XANES spectra obtained at $\mathrm{Mn} \mathrm{K}$-edge for different oxides with different metal oxidation states, metallic $\mathrm{Mn}, \mathrm{MnO}(2+), \mathrm{Mn}_{2} \mathrm{O}_{3}(3+)$ and $\mathrm{MnO}_{2}$ $(4+)$. The comparison between the spectra indicates that the Mn ions in our samples assume the $2+$ oxidation state. As the XANES spectrum is very sensitive to the local environment of the absorbing atom, it can be also used to probe the site were the dopant ions are placed in the analyzed structure. The pre-edge peak originates by a $s \rightarrow d$ transition, however, the dipolar selection rules do not allow this excitation. Its observation is associated to a $p-d$ hybridization, which in turn is only possible if the Mn site does not contain an inversion center, as happens in tetrahedral configuration. In Fig. 4(a) we can see clearly a relative intense peak at the pre-edge region, what can lead us to conclude that in our samples the $\mathrm{Mn}^{2+}$ ions are located in tetrahedral sites, what would be expected considering that the $\mathrm{Mn}^{2+}$ are replacing the $\mathrm{Zn}^{2+}$ in the $\mathrm{ZnO}$ wurtzite structure $[28,29]$.

The shape of the absorption edge depends on the unfilled local density of states and the coordination symmetry of the absorbing element. Fig. 4(b) show extended XANES spectra obtained for the samples at $\mathrm{Mn}$ and $\mathrm{Zn}$ K-edge. We observed a very good correlation between the oscillations for both samples. Unlike other magnetic semiconductors where the transition metal atoms are in interstitial sites in the host matrix $[30,31]$, our XANES results is a strong indication of the substitutional character of $\mathrm{Mn}$ ions in the $\mathrm{ZnO}$ wurtzite matrix [29].

The short-range structural data provided by extended X-ray absorption fine structure (EXAFS) spectroscopy offer elementspecific insight, furnishing quantitative information about the
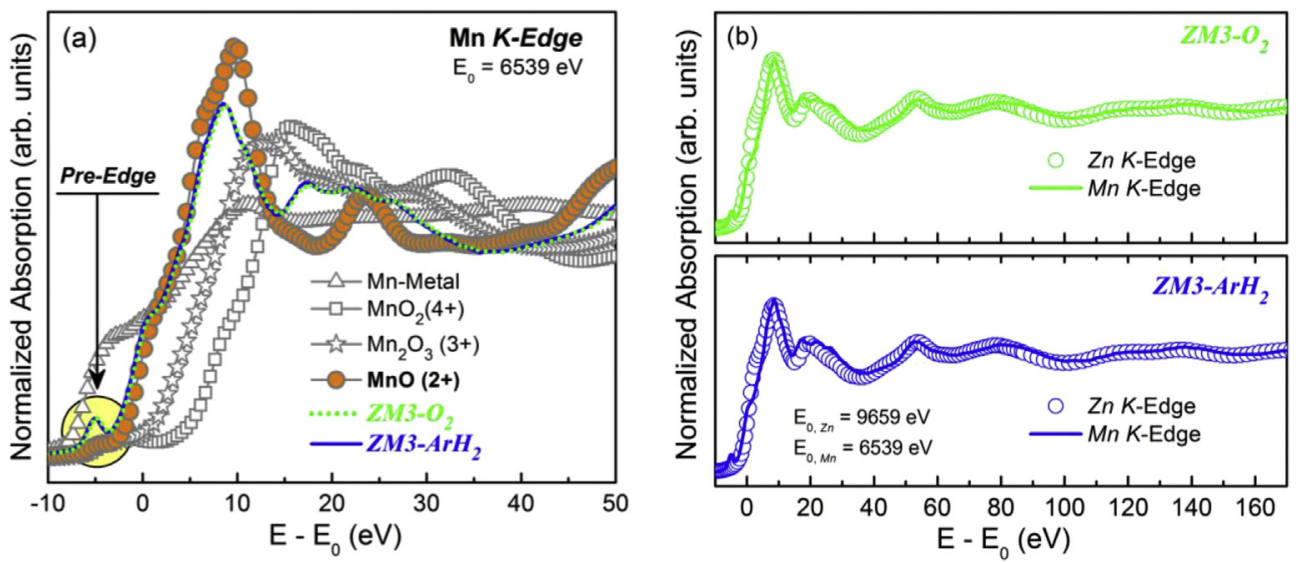

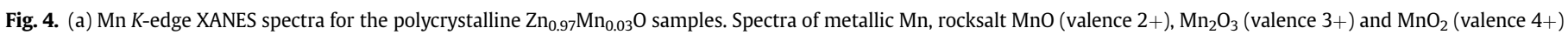
are also shown. (b) Comparison of the $\mathrm{Mn}$ and $\mathrm{Zn} \mathrm{K}$-edge XANES spectra for the $\mathrm{ZM}_{3}-\mathrm{O}_{2}$ and the $\mathrm{ZM}_{3}-\mathrm{ArH}_{2}$ samples. 

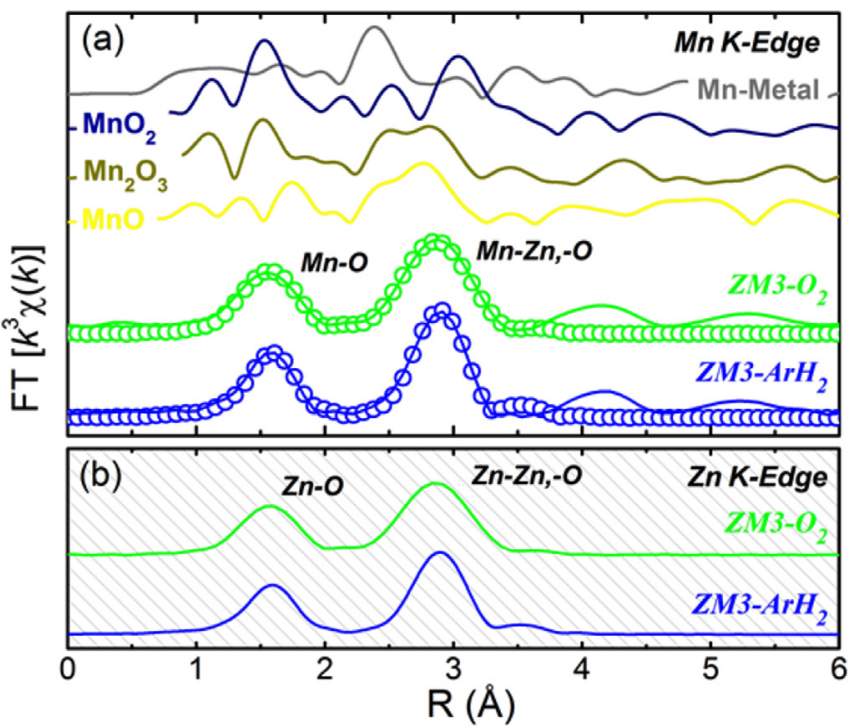

Fig. 5. Experimental and fitted modulus of $k^{3}$ weighted Fourier transform (FT) for the polycrystalline $\mathrm{Zn}_{0.97} \mathrm{Mn}_{0.03} \mathrm{O}$ and reference samples. Solid lines are experimental data, and open symbols represent fittings using the parameters listed in Table 3. Results for the measurements at (a) Mn K-edge and at (b) $\mathrm{Zn} \mathrm{K}$-edge. The spectra are offset for clarity.

numbers, positions, and identities of atoms surrounding the absorbing element, as well as structural disorder within the coordination spheres. The fitted $k^{3}$-weighted Fourier transforms of the polycrystalline $\mathrm{Zn}_{0.97} \mathrm{Mn}_{0.03} \mathrm{O}$ samples are shown in Fig. 5(a). The EXAFS data were obtained at Mn $\mathrm{K}$-edge for the studied samples, $\mathrm{ZM} 3-\mathrm{O}_{2}$ and $\mathrm{ZM} 3-\mathrm{ArH}_{2}$, and for metallic $\mathrm{Mn}, \mathrm{MnO}(2+), \mathrm{Mn}_{2} \mathrm{O}_{3}$ $(3+)$ and $\mathrm{MnO}_{2}(4+)$ reference powders. The results obtained at $\mathrm{Zn}$ $\mathrm{K}$-edge for the $\mathrm{ZM} 3-\mathrm{O}_{2}$ and $\mathrm{ZM} 3-\mathrm{ArH}_{2}$ samples are presented in Fig. 5(b). We observe that the EXAFS data for Mn-doped samples are very similar to each other but quite different to those for the metallic Mn and the Mn oxides. On the other hand, we observe that the EXAFS data are quite comparable to those obtained at $\mathrm{Zn} \mathrm{K}$ edge, indicating that the $\mathrm{Mn}^{2+}$ ions in our samples are located at the same environment of $\mathrm{Zn}^{2+}$ ions in the $\mathrm{ZnO}$ wurtzite structure. This remark, with the previous results for XRD, SEM, EDS, Raman and XANES, let us to conclude that $\mathrm{Mn}^{2+}$ ions in our samples are incorporated into the $\mathrm{ZnO}$ wurtzite structure in substitutional character of the $\mathrm{Zn}^{2+}$ ions.

The extraction and fitting of EXAFS spectra were performed using Multi-Platform Applications for X-ray absorption (MAX). $A b$ initio FEFF8.2 [20] code was used to calculate the theoretical spectra. To obtain quantitative structural data concerning the first coordination shells, the neighborhood of $\mathrm{Mn}$ atoms was modeled through the two main peaks (between 1.5 and $3.0 \AA$ ) from FT-EXAFS

Table 3

Mn $K$-edge EXAFS simulation results. $R$ is the distance from the central atom, $N$ is the average coordination number, $\sigma^{2}$ the Debye-Waller factor, and $Q F$ the quality factor.

\begin{tabular}{llllll}
\hline Sample & Shell & $\begin{array}{l}R \\
(\AA)\end{array}$ & $N$ & $\begin{array}{l}\sigma^{2} \\
\left(\times 10^{-3} \AA^{2}\right)\end{array}$ & $Q F$ \\
\hline ZM3-O 2 & Mn-O & $2.04(1)$ & $4.2(3)$ & 2.5 & 3.18 \\
& Mn-Zn & $3.21(1)$ & $5.6(3)$ & 4.1 & \\
& Mn-Zn & $3.30(1)$ & $5.4(3)$ & 4.1 & \\
& Mn-O & $3.80(1)$ & $5.9(6)$ & 2.5 & 3.46 \\
ZM3-ArH $_{2}$ & Mn-O & $2.04(1)$ & $4.3(3)$ & 2.5 & \\
& Mn-Zn & $3.23(1)$ & $5.4(3)$ & 4.1 & \\
& Mn-Zn & $3.31(1)$ & $4.1(3)$ & 4.1 & \\
& $\mathrm{Mn}-\mathrm{O}$ & $3.78(1)$ & $6.6(6)$ & 2.5 & \\
\hline
\end{tabular}

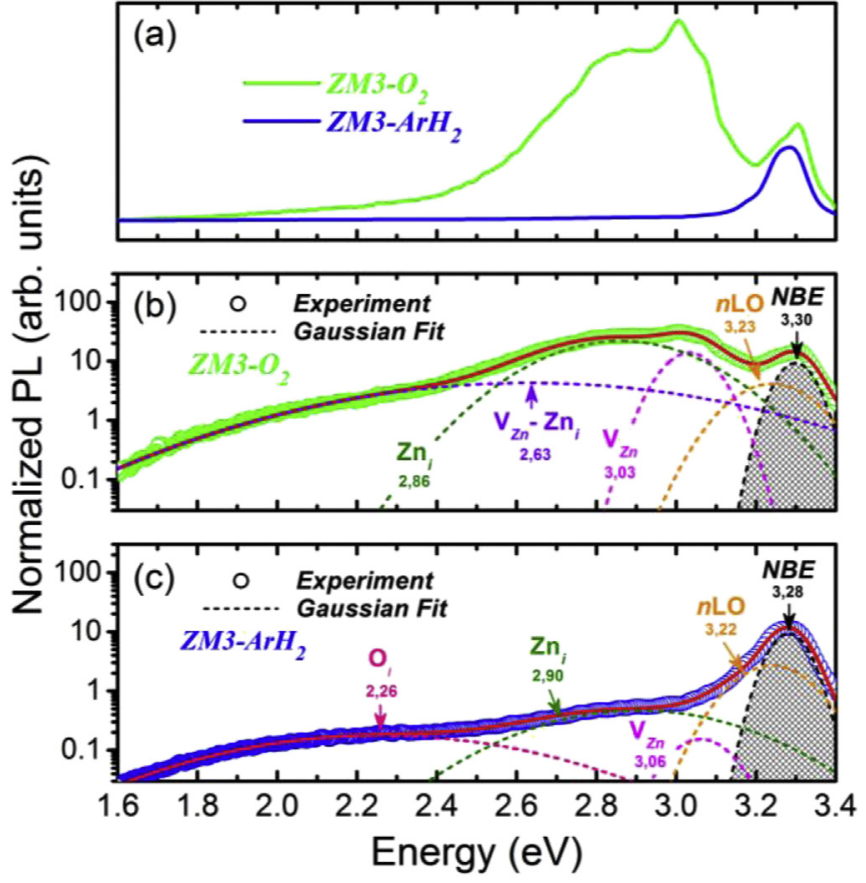

Fig. 6. (a) Room temperature PL spectra of the polycrystalline $\mathrm{Zn}_{0.97} \mathrm{Mn}_{0.03} \mathrm{O}$ samples. The spectra were normalized by the integrated area of the NBE emission for comparison. (b) and (c) present the experimental spectra and the Gaussian fit (in logarithmic scale) for the as prepared $\left(\mathrm{ZM} 3-\mathrm{O}_{2}\right)$ and the annealed $\left(\mathrm{ZM} 3-\mathrm{ArH}_{2}\right)$ samples, respectively.

in Fig. 5(a). In all fits, we considered single and multi-scattering paths corresponding to the four successive atomic shells around Mn substitutionally placed at Zn-sites of the ZnO structure according to the hexagonal wurtzite with $\mathrm{PG}_{3} \mathrm{mc}$ space group. Fig. 5(a) shows a good agreement between experimental (lines) and simulated (symbols) results.

The interatomic distance $(R)$, the coordination number $(N)$, and the reliability of the fit, determined by a quality factor $(Q F)[32]$ and Debye-Waller factor $\left(\sigma^{2}\right)$, relative to the fits are reported in Table 3. The first shell $(\mathrm{Mn}-\mathrm{O})$ coordination number is around 4, consistent with a $\mathrm{Mn}^{2+}$ substitutional for tetrahedral $\mathrm{Zn}^{2+}$ ions in the $\mathrm{ZnO}$ wurtzite structure. We also observe that the interatomic distances, according to our calculation, are not affected by the annealing process.

\subsection{Photoluminescence (PL) and Hall effect}

It is well known that PL is a useful tool for the investigation of intrinsic point defects in $\mathrm{ZnO}$, including oxygen vacancy $\left(V_{0}\right)$, zinc vacancy $\left(V_{Z n}\right)$, interstitial oxygen $\left(O_{i}\right)$, and interstitial zinc $\left(Z n_{\mathrm{i}}\right)$. Fig. 6(a) shows the obtained room temperature PL spectra of $\mathrm{Zn}_{0.97} \mathrm{Mn}_{0.03} \mathrm{O}$ samples. The measured spectra are characterized by a near-band-edge (NBE) emission centered at around $3.30 \mathrm{eV}$, dominated by the 1LO phonon replica of free excitons [33], and a broad band at lower energies, specifically from 3.20 down to $1.6 \mathrm{eV}$, associated to different transitions between different defect levels located inside the energy gap [34]. We observed that the spectrum for the $\mathrm{ZM} 3-\mathrm{O}_{2}$ sample is governed by the defect broad band emission; on the other hand, the spectrum for the $\mathrm{ZM} 3-\mathrm{ArH}_{2}$ sample is governed mainly by the NBE emission. These results let us to conclude that thermal treatment performed on this sample removed considerable amount of the defects previously presented in the as prepared sample. In attempt to identify the band 
Table 4

Gaussian fit parameters obtained for PL spectra of the polycrystalline $\mathrm{Zn}_{0.97} \mathrm{Mn}_{0.03} \mathrm{O}$ samples.

\begin{tabular}{lllll}
\hline Sample & $\begin{array}{l}\text { Energy } \\
(\mathrm{eV})\end{array}$ & $\begin{array}{l}\text { FWHM } \\
(\mathrm{eV})\end{array}$ & $\begin{array}{l}\text { Area } \\
(\mathrm{a} . \mathrm{u} .)\end{array}$ & Emission \\
\hline $\mathrm{ZM}^{\mathrm{Z}}-\mathrm{O}_{2}$ & $3.30(1)$ & $0.085(4)$ & 1 & $\mathrm{NBE}$ \\
& $3.23(1)$ & $0.180(2)$ & $0.9(2)$ & $\mathrm{nLO}$ \\
& $3.03(1)$ & $0.121(3)$ & $2.1(1)$ & $V_{\mathrm{Zn}}$ \\
& $2.86(3)$ & $0.333(3)$ & $9.2(4)$ & $\mathrm{Zn}$ \\
& $2.63(5)$ & $0.800(4)$ & $4.3(5)$ & $V_{\mathrm{Zn}}-\mathrm{Zn}_{\mathrm{i}}$ \\
$\mathrm{ZM}_{3}-\mathrm{ArH}_{2}$ & $3.28(1)$ & $0.086(1)$ & 1 & $\mathrm{NBE}$ \\
& $3.22(2)$ & $0.170(2)$ & $0.570(2)$ & $n \mathrm{LO}$ \\
& $3.06(1)$ & $0.140(3)$ & $0.027(6)$ & $V_{\mathrm{Zn}}$ \\
& $2.90(3)$ & $0.449(2)$ & $0.264(5)$ & $\mathrm{Zn}_{\mathrm{i}}$ \\
& $2.26(5)$ & $0.670(2)$ & $0.148(4)$ & $\mathrm{O}_{\mathrm{i}}$ \\
\hline
\end{tabular}

emissions and the correlated specific point defects presented in each sample, the measured spectra were fitted by Gaussians following representative experimental and theoretical references [35-37]. Fig. 6(b) and (c) show the best fits obtained, the spectra were normalized by the integrated area of the NBE emission. The obtained fit parameters are listed in Table 4.

First we call attention to the small red shift of the NBE emission for the $\mathrm{ZM} 3-\mathrm{ArH}_{2}$ sample as compared to the same emission for the $\mathrm{ZM} 3-\mathrm{O}_{2}$ sample $(3.30-3.28 \mathrm{eV}$ ). We observe also that the average intensity of the defect emission bands for the $\mathrm{ZM} 3-\mathrm{O}_{2}$ sample is one order of magnitude greater than those for the $\mathrm{ZM} 3-\mathrm{ArH}_{2}$ sample. Just below the NBE emission we identify a broad band, indexed as $n \mathrm{LO}$, associated to higher-order phonon replicas of the NBE emission [33]. In the sequence we identify three defect emission bands in the spectra for both samples centered at 3.03/3.06 and 2.86/ $2.90 \mathrm{eV}\left(\mathrm{ZM} 3-\mathrm{O}_{2} / \mathrm{ZM} 3-\mathrm{ArH}_{2}\right)$. The bands at 3.03/3.06 and 2.86/ $2.90 \mathrm{eV}$ are associated with zinc vacancies $\left(V_{\mathrm{Zn}}\right)$ and interstitial zinc $\left(Z n_{i}\right)$, respectively. For the $Z M 3-O_{2}$ sample we observe, in the sequence, a very broad band around $2.63 \mathrm{eV}$ which can be indexed to transitions between the defect levels associated to $V_{\mathrm{Zn}}(3.03 \mathrm{eV})$ and $Z n_{\mathrm{i}}(2.86 \mathrm{eV})$. Finally, for the $\mathrm{ZM} 3-\mathrm{ArH}_{2}$ sample we observe a band emission at $2.26 \mathrm{eV}$ which can be indexed to interstitial oxygen $\left(O_{\mathrm{i}}\right)$.

These results can be correlated to the XRD data obtained from the Rietveld refinement (Tables 1 and 2). The red shift of the NBE for the $\mathrm{ZM} 3-\mathrm{ArH}_{2}$ sample can be associated with the small increase on the lattice parameters observed for this sample. Concerning the elemental occupation rate, the $\mathrm{ZM} 3-\mathrm{O}_{2}$ sample presents a lower cationic occupation rate, which is associated to higher density of zinc vacancies $\left(V_{\mathrm{Zn}}\right)$ due to the migration of the $\mathrm{Zn}^{2+}$ to interstitial sites $\left(Z n_{\mathrm{i}}\right)$. As we presented before, for the as prepared sample we observe a relative intense defect emission bands associated to defects at the $Z n$ sites $\left(V_{Z n}\right.$ and $Z n_{\mathrm{i}}$ ), while for the annealed sample the intensity of these emission bands decreases considerably, indicating that the densities of $V_{\mathrm{Zn}}$ and $Z n_{\mathrm{i}}$ are relatively higher for the $\mathrm{ZM} 3-\mathrm{O}_{2}$ sample, as was pointed by the XRD data.

The indexation of the defect emission bands can be corroborated by associating the PL results to the measurements of the carrier densities. The electron concentration in undoped $\mathrm{ZnO}$ can reach the order of $10^{19} \mathrm{~cm}^{-3}$ due to the presence of intrinsic or extrinsic defects [38], the nature of this defects is still also a matter of debate [39]. However, for the TM-doped oxides the dopants introduce compensating defects into the system that lead to a significant decrease of the electron concentration [40-43]. In our case, the Hall effect measurements reveal that both studied samples are, as expected, $n$-type. For the $\mathrm{ZM} 3-\mathrm{O}_{2}$ sample the obtained electron density was $n_{\mathrm{O}_{2}}=4.42 \times 10^{17} \mathrm{~cm}^{-3}$, and for the ZM3$\mathrm{ArH}_{2}$ sample $n_{\mathrm{ArH}_{2}}=1.07 \times 10^{17} \mathrm{~cm}^{-3}$; corresponding to a decrease in the electron density of $76 \%$ between the samples after the annealing. The observed decrease in the carrier density for the annealed sample can be explained in terms of the changes between the relative contribution between donor and acceptor defect bands. In a general way, there is a consensus that the levels associated to defects at the $\mathrm{Zn}$ sites are shallow, levels associated to $V_{\mathrm{Zn}}$ are of acceptor character, and those associated to $Z n_{\mathrm{i}}$ are of donor character [35-37]. Concerning the oxygen site, the levels associated to $V_{\mathrm{O}}$ are deep donors, while levels associated to $O_{\mathrm{i}}$ are shallow acceptors. Here we define the parameter $R$ as the ratio of the intensity of the band with the donor character $\left(I_{Z n_{\mathrm{i}}}\right)$ and the intensities of the bands with acceptor character $\left(I_{V_{Z_{n}}}+I_{O_{\mathrm{i}}}\right)$ obtained by the fit performed for the spectra measured for each sample, in this way $R=I_{Z n_{\mathrm{i}}} /\left(I_{V_{\mathrm{Zn}}}+I_{O_{\mathrm{i}}}\right)$. From the values listed in Table 4 we obtain for the $\mathrm{ZM} 3-\mathrm{O}_{2}$ sample $R_{\mathrm{O}_{2}}=4.4 \pm 0.4$ and for the $\mathrm{ZM} 3-\mathrm{ArH}_{2}$ sample $R_{\mathrm{ArH}_{2}}=1.51 \pm 0.08$, i.e., for the annealed sample there are less donor defects than for the as prepared sample. Considering the percentages, we observe a decrease of the parameter $R$ of $65 \%$, in good agreement with the decrease observed for the electron densities, what corroborates the indexation of the bands of defects.

The structural analysis confirms that $\mathrm{Mn}$ ions are located at the $\mathrm{Zn}$-sites in the $\mathrm{ZnO}$ wurtzite structure in ours samples. The results exclude the presence of magnetic extrinsic sources as Mn-rich nanocrystals and segregated secondary magnetic phases. The PL results reveal that the density of point defects is annealed out from the as prepared sample by the thermal treatment. With these conclusions we proceed to the magnetic characterization.
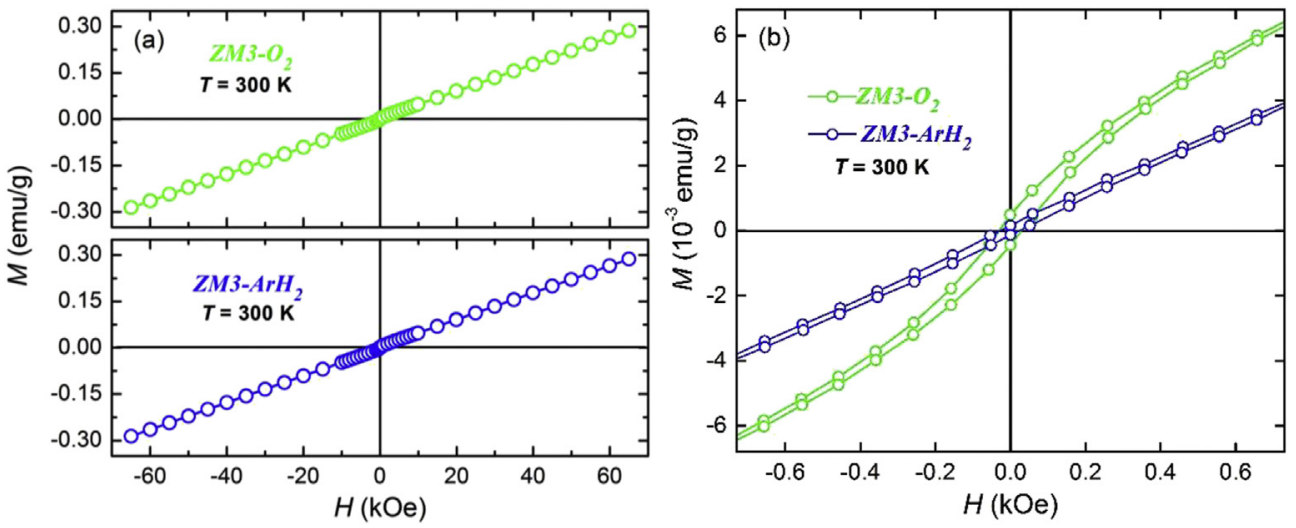

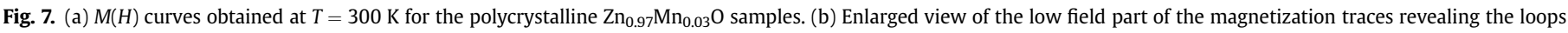
related to the FM phase. 


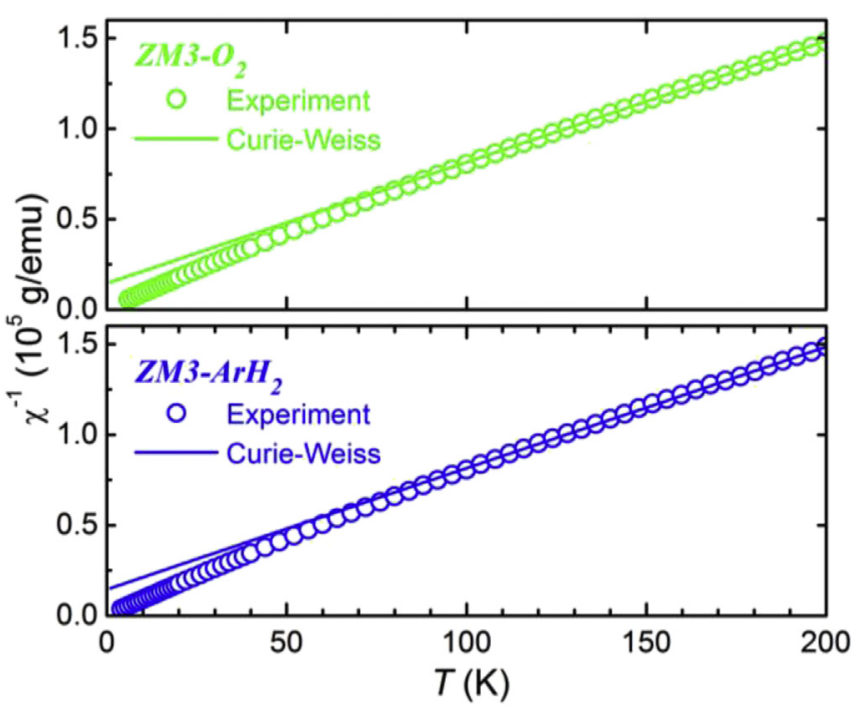

Fig. 8. Inverse susceptibility as a function of the temperature of the paramagnetic phase of $\mathrm{Mn}$ ions at the polycrystalline $\mathrm{Zn}_{0.97} \mathrm{Mn}_{0.03} \mathrm{O}$ samples. The best fit of the high temperature data to Curie-Weiss law is shown as solid lines.

\subsection{Magnetic characterization}

Fig. 7 presents the magnetization $(M)$ of the studied samples measured at $300 \mathrm{~K}$ as a function of the magnetic field $(H)$, the $M(H)$ curves. In addition to the usual paramagnetic (PM) phase of the Mn ions [23,44,45], the data show the existence of a ferromagnetic (FM) phase. The contribution of the FM phase is relatively small as compared to the PM phase. The magnetic parameters related to the PM and the FM phases were analyzed separately by subtracting one component from another.

The temperature variation of the magnetic susceptibility of the PM phase has been determined from the $\Delta M / \Delta H$ data obtained for temperatures in the rage of $300-1.66 \mathrm{~K}$ and field values between 0.1 and $1 \mathrm{~T}$. The inverse of the $d c$ magnetic susceptibility as a function of temperature is presented in Fig. 8. The inverse of the susceptibility of the PM phase in the high temperature regime is well described by a Curie-Weiss law: $\chi(T)=C /(T-\theta)$; where $C$ is the Curie constant per gram and $\theta$ is the Curie-Weiss temperature. $C$ and $\theta$ are both linear functions of the Mn content $x_{\mathrm{M}}: C=x_{\mathrm{M}} \times C_{0}$ and $\theta=x_{\mathrm{M}} \times \theta_{0}$, where $C_{0}=N\left(g \mu_{\mathrm{B}}\right)^{2} S(S+1) / 3 \mathrm{k}_{B}$ and $\theta_{0}=2 z S(S+1) J_{1} /$ $3 k_{\mathrm{B}}$. Here, $N$ is the total number of cations per gram, $g$ and $S$ are respectively the effective Landé factor and the spin of the $\mathrm{Mn}^{2+}$ ions ( $g=2.0016, S=J=5 / 2$ ) [46], $\mu_{\mathrm{B}}$ is the Bohr magneton, $z$ is the number of nearest neighbors ( $z=12$ in the wurtzite structure), $J_{1}$ is the effective exchange integral constant between the nearestneighbors, and $k_{\mathrm{B}}$ is the Boltzmann constant. The Mn concentration obtained through the magnetic characterization $\left(x_{\mathrm{M}}\right)$ and the effective exchange integral constant $\left(J_{1} / k_{\mathrm{B}}\right)$ are displayed in Table 5. The values found for $x_{\mathrm{M}}$ are in excellent agreement with the nominal values and those measured by $\operatorname{EDS}\left(x_{\mathrm{EE}}\right)$, even considering

\section{Table 5}

Parameters determined from the magnetic measurements. $x_{M}$ is the Mn concentration of the paramagnetic phase. $J_{1} / k_{B}$ is the effective exchange integral constant between the nearest-neighbors. $x_{\mathrm{ME}}$ and $T_{\mathrm{E}}$ are the effective Mn concentration and the effective temperature determined by the fit of the magnetization trace to the modified Brillouin function at the temperature $T=1.66 \mathrm{~K}$.

\begin{tabular}{lllll}
\hline Sample & $x_{\mathrm{M}}$ & $J_{1} / k_{B}(\mathrm{~K})$ & $x_{\mathrm{ME}}$ & $T_{\mathrm{E}}(\mathrm{K})$ \\
\hline $\mathrm{ZM}_{3}-\mathrm{O}_{2}$ & $0.0278(5)$ & $-11.8(7)$ & $0.0206(1)$ & $1.82(2)$ \\
$\mathrm{ZM}-\mathrm{ArH}_{2}$ & $0.0278(5)$ & $-12.3(7)$ & $0.0209(1)$ & $1.66(2)$ \\
\hline
\end{tabular}

that fraction of Mn ions are ferromagnetically coupled. We observe also that both samples present negative exchange constants, indicating a large antiferromagnetic (AF) exchange interaction between $\mathrm{Mn}$ ions in the PM phase. The obtained values of the $J_{1} / k_{\mathrm{B}}$ are consistent with previous results on $\mathrm{Zn}_{1-x} \mathrm{Mn}_{x} \mathrm{O}$ bulk samples for which the exchange interaction between first neighbors is antiferromagnetic (AF) with a mean value of $J_{1} / k_{\mathrm{B}}=-13.8(7) \mathrm{K}$ $[23,44,45]$.

Further information about the exchange interaction between the $\mathrm{Mn}$ ions and their distribution over the volume of the samples can be addressed by analyzing the $M(H)$ paramagnetic curve obtained at low temperature [47]. The paramagnetic contribution traces obtained at $T=1.66 \mathrm{~K}$ for the $\mathrm{ZM} 3-\mathrm{O}_{2}$ and the $\mathrm{ZM} 3-\mathrm{ArH}_{2}$ samples are displayed in Fig. 9(a) and (b), respectively. The data have been fitted to a modified Brillouin function (MBF). The fit gave the value of the effective Mn concentration $\left(x_{\mathrm{ME}}-\right.$ Mn ions interacting paramagnetically) and the value of the effective temperature $\left(T_{\mathrm{E}}\right)$. The obtained values of $x_{\mathrm{ME}}$ and $T_{\mathrm{E}}$ are given also in Table 5. From $x_{\mathrm{ME}}$ we determined the technical saturation magnetization value $\left(M_{\mathrm{TS}}\right)$. The data are displayed in Fig. 9(c). There, the predicted variation of the $M_{\mathrm{TS}}$ as a function of $x$ for a model with one exchange interaction between first neighbors and assuming a random distribution of the $\mathrm{Mn}$ ions is also shown. For that model, $M_{\mathrm{TS}}$ is given by

$M_{\mathrm{TS}}=\left(P_{\mathrm{S}}+P_{\mathrm{OT}} / 3+P_{\mathrm{CT}} / 15+P_{\mathrm{PQ}} / 2+P_{\mathrm{FQ}} / 5+P_{\mathrm{Other}} / 5\right) M_{\mathrm{S}}$,

where $M_{\mathrm{S}}$ is the value of the true saturation magnetization (paramagnetic case with no relevant exchange interaction) and $P_{i}$ is the probability that a magnetic ion belongs to each of these $i$ type of cluster: $\mathrm{S}=$ Single, $\mathrm{OT}=$ Open Triplet, $\mathrm{CT}=$ Closed Triplet, $\mathrm{PQ}=$ Propeller Quartet, FQ = Funnel Quartet, Other = cluster larger
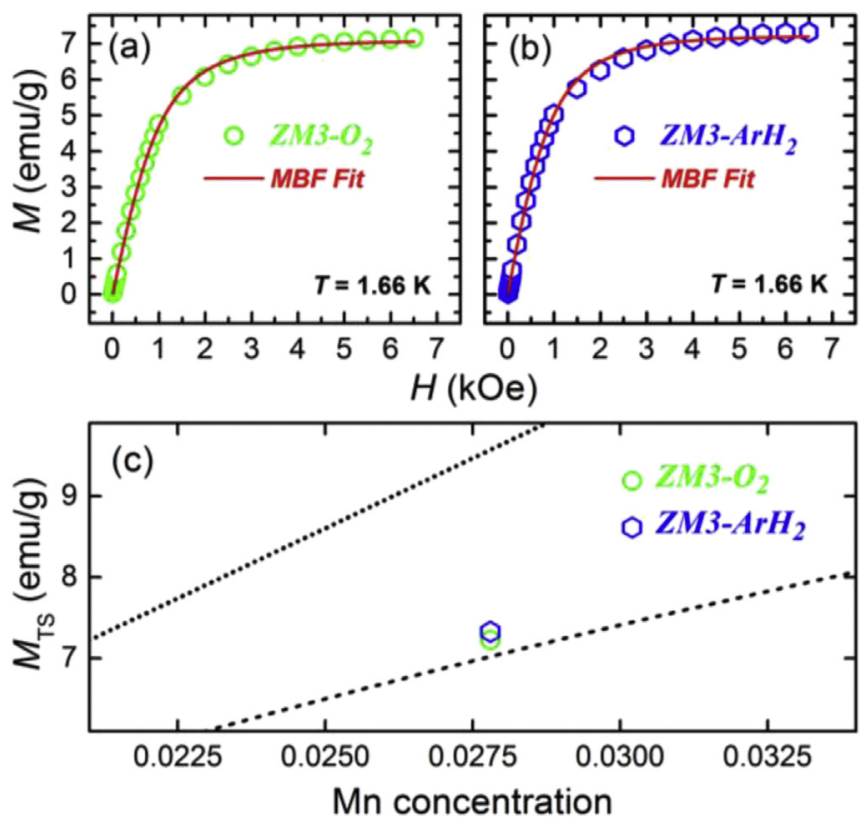

Fig. 9. Magnetization as a function of the magnetic field obtained at low temperature for the (a) as prepared and the (b) annealed samples. The symbols are the experimental data. The red lines represent the result of the fit of the data by a modified Brillouin function (MBF). (c) Technical saturation magnetization $\left(M_{\mathrm{TS}}\right)$ for the studied samples as a function of the Mn concentration $(x)$. The dotted line illustrates the case of a PM phase with no exchange interaction. The dashed line represents the prediction of model with one exchange interaction between first neighbors and assuming a random distribution of the magnetic ions. (For interpretation of the references to color in this figure legend, the reader is referred to the web version of this article.) 
than quartet. The full expression for $M_{\mathrm{TS}}$, including the probabilities $\left(P_{i}\right)$, can be found in Refs. $[48,49]$.

We observe in Fig. 9(c) that the measured $M_{\mathrm{TS}}$ for the $\mathrm{ZM} 3-\mathrm{O}_{2}$ and for the $\mathrm{ZM} 3-\mathrm{ArH}_{2}$ samples agree very well with the theoretical curve calculated through Eq. (1). This result leads us to conclude that the PM phase is characterized by a large antiferromagnetic exchange interaction between Mn ions, corroborating the susceptibility data, and that the $\mathrm{Mn}$ ions in the studied samples are randomly distributed over their volumes, which correspond to a good homogeneity of the Mn concentration. We can also observe that the measured $T_{\mathrm{E}}$ for both studied samples are very close to the temperature of the measurements, $T=1.66 \mathrm{~K}$. The differences between the measuring $(T)$ and the effective $\left(T_{\mathrm{E}}\right)$ temperatures are caused by distant-neighbor interactions [50]. The observed small differences reflect that the distant-neighbor antiferromagnetic interactions between the $\mathrm{Mn}$ ions in the $\mathrm{ZnO}$ wurtzite structure have no considerable magnitude as compared to the $1.66 \mathrm{~K}$, as we would expect [51]. It is worth also to point out that all the obtained magnetic parameters related to the PM phase for the as prepared and annealed samples are quite similar, what means that the annealing process and the induced changes in the defect densities has no effect over this phase.

Fig. 10 shows the FM phase at $300 \mathrm{~K}$ obtained after the subtraction of the PM phase. The $M_{\mathrm{S}}$ for the $\mathrm{ZM} 3-\mathrm{ArH}_{2}$ sample is at least 3-fold smaller than that for the $\mathrm{ZM} 3-\mathrm{O}_{2}$ sample. The $M_{\mathrm{S}}$ is found to be temperature independent for both samples (lowerright inset of Fig. 10). At room temperature $H_{\mathrm{C}}$ is around 40 Oe and 100 Oe for the as prepared and for the annealed samples, respectively (upper-left inset of Fig. 10). The magnetic moment per Mn atom $(\mu)$ in the studied samples was determined following calculation performed in Ref. [52]. Table 6 present the used input parameters and the obtained $\mu$ for each sample. In the Mn-doped $\mathrm{ZnO}$ system, prepared from high-purity $\mathrm{ZnO}$ and $\mathrm{MnO}$ powders, the most probably segregated phases are Mn metallic clusters, Mn oxides, $\mathrm{MnO}$ and $\mathrm{Mn}_{2} \mathrm{O}_{3}$, and the ternary spinel compound $\mathrm{ZnMn}_{2} \mathrm{O}_{4}$. All of them are well known paramagnetic materials at room temperature [53,54], what lead us to conclude that the observed RTFM cannot be explained in terms of any secondary phase. We obtained an average value of $5.5 \mu_{\mathrm{B}} / \mathrm{Mn}$ cation, a value

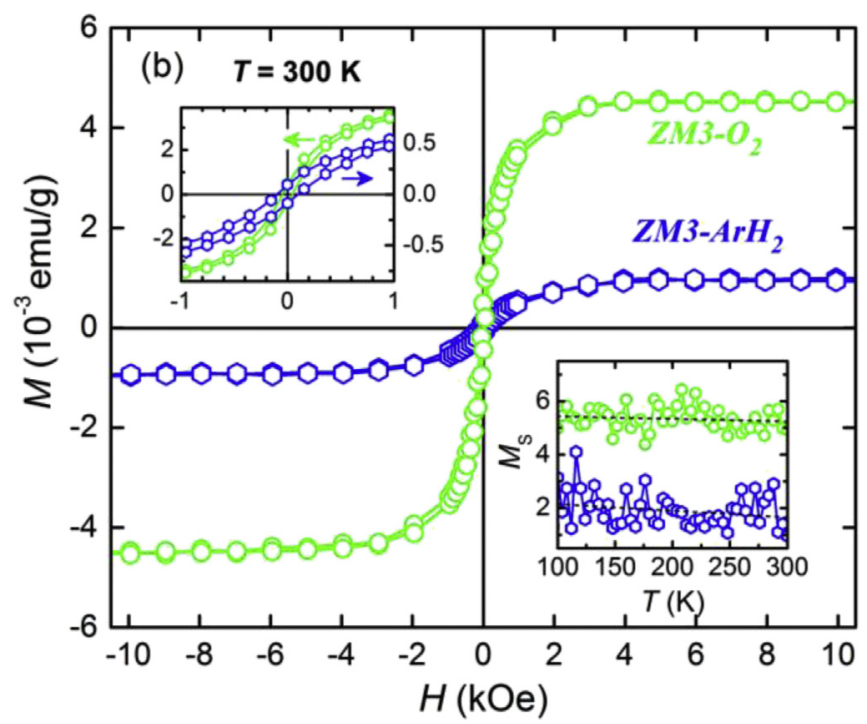

Fig. 10. Subtracting the paramagnetic contribution from magnetic measurements, $M(H)$ curves, the hysteresis curves related to the FM phase is clearly observed. The insets show the coercive field (upper-left) and the temperature variation of the saturation value of the magnetization of the FM phase (lower-right).
Table 6

Parameters of the magnetic characterization: effective Mn concentration $\left(x_{\mathrm{EE}}\right)$ measured by EDS, number of $\mathrm{Mn}$ atoms per gram $\left(N_{\mathrm{Mn}}\right)$, saturation magnetization $\left(M_{\mathrm{S}}\right)$, paramagnetic susceptibility $\left(\chi_{\mathrm{P}}\right)$, and estimated magnetic moment per $\mathrm{Mn}$ atom $(\mu)$.

\begin{tabular}{llllll}
\hline Sample & $x_{\mathrm{EE}}$ & $\begin{array}{l}N_{\mathrm{Mn}} / \mathrm{g} \\
\left(\times 10^{20}\right)\end{array}$ & $\begin{array}{l}M_{\mathrm{S}} \\
(\mathrm{emu} / \mathrm{g})\end{array}$ & $\begin{array}{l}\chi_{\mathrm{P}} \\
(\mathrm{emu} / \mathrm{gOe})\end{array}$ & $\begin{array}{l}\mu \\
\left(\mu_{\mathrm{B}}\right)\end{array}$ \\
\hline $\mathrm{ZM}-\mathrm{O}_{2}$ & $0.028(6)$ & 2.0795 & 0.0044 & $4.34 \times 10^{-6}$ & 5.49 \\
$\mathrm{ZM}-\mathrm{ArH}_{2}$ & $0.031(2)$ & 2.0795 & 0.0010 & $4.35 \times 10^{-6}$ & 5.50 \\
\hline
\end{tabular}

quite close to the expected one for the half-filled $d$ band of $\mathrm{Mn}^{2+}$ ion [55]. Such high moments per cation are inexplicable in terms of possible known ferromagnetic phases [56]. So, it is also evidence that the observed RTFM behavior is not due ferromagnetic secondary phases.

The nature of the observed RTFM can be analyzed under the scope of the BMP model. Here, a long range magnetic order occurs when two conditions are satisfied, the dopant concentration $(x)$ have to be lower than the dopant percolation threshold $\left(x_{\mathrm{P}}\right)$ and the percentage of defects $(\delta)$ have to be larger than the polaron percolation threshold $\left(\delta_{\mathrm{P}}\right)$, for the $\mathrm{ZnO}$ system $\delta_{\mathrm{P}}=0.0015$ and $x_{\mathrm{P}}=0.18$ [8]. Therefore, in the scenario of the BMP model, for a specific dopant concentration, the FM properties of doped oxide matrix would be modulated by its density of defects. Also, in the context of the BMP model, the RTFM require hybridization and charge transfer from the donor-derived impurity band related to the shallow donor defects to the unoccupied $3 d$ states of the TM doping ions at the Fermi level.

In our samples the concentration of Mn ions $(x=0.03)$ is well below the percolation limit of the $\mathrm{ZnO}$ doping. However, as we have pointed before, assuming a random distribution of the Mn ions over the volume of the $\mathrm{ZnO}$ matrix, $69.4 \%$ of the $\mathrm{Mn}$ ions are isolated (singles), and the remaining fraction are found in one of the following antiferromagnetic cluster arrangement: pairs, triplets, quartets, etc. [47]. Taking into account that only the noncompensated moments could be ferromagnetically coupled through polarons, the effective Mn concentration that have to be considered in our samples is, in fact, even lower than $x=0.03$. Regarding the density of defects, the PL results clear reveals for the as prepared sample a higher concentration of defects mainly related to defects at the zinc sites $\left(V_{\mathrm{Zn}}\right.$ and $\left.Z n_{\mathrm{i}}\right)$, and that under the thermal treatment these defects are almost annealed out with the introduction of a relative small density of defects at anionic sites $\left(O_{\mathrm{i}}\right)$. Among the identified defects, $Z n_{\mathrm{i}}$ is the only one that corresponds to a shallow defect, necessary to form a BMP [35-37]. Therefore, the observed decrease of the $M_{\mathrm{S}}$ with the annealing process is consistent with the BMP model once considering the $Z n_{\mathrm{i}}$ as the shallow donor defect associated to the formed BMPs. However, for the $\mathrm{Mn}$ doping in $\mathrm{ZnO}$, the requirement of the charge transfer from donor states to the Mn $3 d$ empty states cannot be completely fulfilled, what would lead, from the theoretical point of view, to a magnetization per cation lower than the observed $5.5 \mu_{\mathrm{B}} /$ Mn [8]. Therefore, we can conclude that the BMP model alone cannot account for the whole observed results. In fact, Coey et al. called attention to this theory difficulty in explain some observation of magnetic moments higher than the spin-only value in the diluted limit, and evoke the contribution of point defects to solve the problem, the called $d^{0}$ ferromagnetism [8]. Here, for the $\mathrm{ZnO}$ matrix the main defects to be considered have proved to be those related to the $\mathrm{Zn}$ sites, in especial, the $\mathrm{Zn}$ vacancies $\left(V_{\mathrm{Zn}}\right)$ [57-59]. Therefore, since the density of $V_{Z n}$ in our samples are considerable, they would account, together with the Mn ions coupled ferromagneticaly trough the magnetic polarons (BMP model), to the observed $5.5 \mu_{\mathrm{B}} / \mathrm{Mn}$. Also, the lower measured $\mathrm{M}_{\mathrm{S}}$ for the $\mathrm{ZM} 3-\mathrm{ArH}_{2}$ 
sample can be explained in terms of the reduction of the $V_{\mathrm{Zn}}$ after the annealing process. What let us to conclude that, by considering both theoretical models, BMP and $d^{0}$ ferromagnetism, the magnetic behavior observed for our Mn-doped ZnO samples are direct related to defects at $\mathrm{Zn}$ sites.

\section{Conclusions}

In summary, we have presented a complete microstructure and magnetic analysis of bulk polycrystalline $\mathrm{Zn}_{0.97} \mathrm{Mn}_{0.03} \mathrm{O}$ samples prepared by the standard solid-state reaction method. Structural results confirm that $\mathrm{Mn}^{2+}$ ions substitute for $\mathrm{Zn}^{2+}$ ions in the wurtzite $\mathrm{ZnO}$ matrix. There is no indication of Mn-rich nanoclusters or segregated secondary phases in all studied samples. The photoluminescence results, corroborated by the Hall measurements, indicated that the as prepared sample has a higher density of defects mainly associated $V_{\mathrm{Zn}}$ and $Z n_{\mathrm{i}}$, and that the defects were annealed-out by the thermal treatment. Magnetization measurements revealed the coexistence of a main paramagnetic and a ferromagnetic phase in both samples. The analyses of the paramagnetic phase showed a Curie-Weiss behavior of the susceptibility at high temperatures characterized by an AF interaction between Mn ions. By fitting $M(H)$ curves at low temperature $(2 \mathrm{~K}$ ) we conclude for the homogeneous distribution of the Mn ions over the $\mathrm{ZnO}$ volume. Considering the ferromagnetic phase, the saturation magnetization decreases under the annealing process and the vanishing of the density of defects. We conclude for the intrinsic character of the observed room temperature ferromagnetism and its consistent correlation with defects at $\mathrm{Zn}$ sites by analyses under the scope of the BMP theory and $d^{0}$ ferromagnetism.

\section{Acknowledgments}

Support from agencies FAPEMIG (APQ-02600-12), CNPq (476870/2011-9), CAPES (PNPD-2011), FINEP (Ref. 134/08), MINECO (MAT2012-33483) and FAPESP are gratefully acknowledged. We also thank CNPq and CAPES for research fellowships (ACD, AOZ and AM). The authors also acknowledge LNLS for the XAS measurements and Prof. Dr. F. Iikawa and Profa. Dra. M. J. S. Brasil of the Universidade de Campinas (UNICAMP) for the Raman measurements.

\section{References}

[1] S.J. Pearton, C.R. Abernathy, M.E. Overberg, G.T. Thaler, D.P. Norton, N. Theodoropoulou, A.F. Hebard, Y.D. Park, F. Ren, J. Kim, L.A. Boatner, J. Appl. Phys. 93 (2003) 1.

[2] T. Dietl, H. Ohno, F. Matsukura, J. Cibert, D. Ferrand, Science 287 (2000) 1019.

[3] S.J. Pearton, W.H. Heo, M. Ivill, D.P. Norton, T. Steiner, Semicond. Sci. Tech. 19 (2004) R59.

[4] P. Sharma, A. Gupta, K.V. Rao, F.J. Owens, R. Sharma, R. Ahuja, J.M.O. Guillen, B. Johansson, G.A. Gehring, Nat. Mater. 2 (2003) 673.

[5] D.C. Kundaliya, S.B. Ogale, S.E. Lofland, S. Dhar, C.J. Metting, S.R. Shinde, Z. Ma B. Varughese, K.V. Ramanujachary, L. Salamanca-Riba, T. Venkatesan, Nat. Mater. 3 (2004) 709.

[6] S.B. Ogale, Dilute doping, Adv. Mater. 22 (2010) 3125.

[7] S. Dutta, S. Chattopadhyay, A. Sarkar, M. Chakrabarti, D. Sanyal, D. Jana, Prog. Mater. Sci. 54 (2009) 89.

[8] J.M.D. Coey, M. Venkatesan, C.B. Fitzgerald, Nat. Mater. 4 (2005) 173.

[9] M. Ivill, S.J. Pearton, S. Rawal, L. Leu, P. Sadik, R. Das, A.F. Hebard, M. Chisholm, J.D. Budai, D.P. Norton, New J. Phys. 10 (2008) 065002.

[10] S. Ramachandran, J. Narayan, J.T. Prater, Appl. Phys. Lett. 88 (2006) 242503.

[11] K.R. Kittilstved, D.A. Schwartz, A.C. Tuan, S.M. Heald, S.A. Chambers, D.R. Gamelin, Phys. Rev. Lett. 97 (2006) 037203.

[12] D.A. Schwartz, D.R. Gamelin, Adv. Mater. 16 (2004) 2115.
[13] N. Khare, M.J. Kappers, M. Wei, M.G. Blamire, J.L. MacManus-Driscoll, Adv Mater. 18 (2006) 1449.

[14] M.H.F. Sluiter, Y. Kawazoe, P. Sharma, A. Inoue, A.R. Raju, C. Rout U.V. Waghmare, Phys. Rev. Lett. 94 (2005) 187204.

[15] J.M.D. Coey, K. Wongsaprom, J. Alaria, M. Venkatesan, J. Phys. D Appl. Phys. 41 (2008) 134012.

[16] S.G. Koch, E.V. Lavrov, J. Weber, Phys. Rev. B 90 (2014) 205212.

[17] A.C. Larson, R.B. Von Dreele, In General Structure Analysis System (GSAS), in: Los Alamos National Laboratory Report LAUR, 2000.

[18] B.H. Toby, J. Appl. Crystallogr. 34 (2001) 210.

[19] M. Alain, M. Jacques, M.B. Diane, P. Karine, 14th International Conference on X-Ray Absorption Fine Structure (Xafs14), Proceedings, J. Phys. Conf. Ser. 190 (2009) 012034.

[20] A.L. Ankudinov, B. Ravel, J.J. Rehr, S.D. Conradson, Phys. Rev. B 58 (1998) 7565.

[21] E.H. Kisi, M.M. Elcombe, Acta Crystallogr. C 45 (1989) 1867.

[22] R.D. Shannon, Acta Crystallogr. A 32 (1976) 751.

[23] S. Kolesnik, B. Dabrowski, J. Mais, J. Appl. Phys. 95 (2004) 2582.

[24] T.C. Damen, S.P.S. Porto, B. Tell, Phys. Rev. 142 (1966) 570.

[25] R. Cusco, E. Alarcon-Llado, J. Ibanez, L. Artus, J. Jimenez, B.G. Wang, M.J. Callahan, Phys. Rev. B 75 (2007) 165202.

26] Rh Callende, S.S. Sussman, M. Selders, R.K. Chang, Phys. Rev. B 7 (1973) 3788.

[27] X.F. Wang, J.B. Xu, X.J. Yu, K. Xue, J.G. Yu, X.J. Zhao, Appl. Phys. Lett. 91 (2007) 212502

[28] J. Pellicer-Porres, A. Segura, J.F. Sanchez-Royo, J.A. Sans, J.P. Itie, A.M. Flank P. Lagarde, A. Polian, Superlattice Microst. 42 (2007) 251.

[29] G. Martinez-Criado, A. Segura, J.A. Sans, A. Homs, J. Pellicer-Porres, J. Susini, Appl. Phys. Lett. 89 (2006) 061906.

[30] W.T. Geng, K.S. Kim, Phys. Rev. B 68 (2003) 125203.

[31] A. Continenza, G. Profeta, S. Picozzi, Phys. Rev. B 73 (2006) 035212.

[32] S.S. Hasnain, Report on the International Workshops on Standards and Criteria in XAFS. X-ray Absorption Fine Structure, in: Proceedings of the VI International Conference on X-ray Absorption Fine Structures, Ellis Horwood, New York, 1991.

[33] W. Shan, W. Walukiewicz, J.W. Ager, K.M. Yu, H.B. Yuan, H.P. Xin, G. Cantwell J.J. Song, Appl. Phys. Lett. 86 (2005) 191911.

[34] Y.G. Wang, S.P. Lau, X.H. Zhang, H.H. Hng, H.W. Lee, S.F. Yu, B.K. Tay, J. Cryst Growth 259 (2003) 335.

[35] B. Lin, Z. Fu, Y. Jia, Appl. Phys. Lett. 79 (2001) 943.

[36] P.S. Xu, Y.M. Sun, C.S. Shi, F.Q. Xu, H.B. Pan, Nucl. Instr. Meth. Phys. Res. B 199 (2003) 286.

[37] C.X. Xu, X.W. Sun, X.H. Zhang L. Ke, S.J. Chua, Nanotechnology 15 (2004) 856.

[38] T. Minami, H. Sato, H. Nanto, S. Takata, Jpn. J. Appl. Phys. 224 (1985) L781.

[39] M. McCluskey, S. Jokela, J. Appl. Phys. 106 (2009) 071101.

[40] R. Kumar, N. Khare, Thin Solid Films 516 (2008) 1302.

[41] L. Yan, C. Ong, X. Rao, J. Appl. Phys. 96 (2004) 508.

[42] S. Singh, M. Rao, Phys. Rev. B 80 (2009) 045210.

[43] J. Han, P. Mantas, A. Senos, J. Eur. Ceram. Soc. 22 (2002) 49.

[44] J. Spalek, A. Lewicki, Z. Tarnawski, J.K. Furdyna, R.R. Galazka, Z. Obuszko, Phys. Rev. B 33 (1986) 3407.

[45] T. Fukumura, Z.W. Jin, M. Kawasaki, T. Shono, T. Hasegawa, S. Koshihara H. Koinuma, Appl. Phys. Lett. 78 (2001) 958.

[46] P.B. Dorain, Phys. Rev. 112 (1958) 1058.

[47] Y. Shapira, V. Bindilatti, J. Appl. Phys. 92 (2002) 4155.

[48] Y. Shapira, S. Foner, D.H. Ridgley, K. Dwight, A. Wold, Phys. Rev. B 30 (1984) 4021.

[49] M.T. Liu, Y. Shapira, E. terHaar, V. Bindilatti, E.J. McNiff, Phys. Rev. B 54 (1996) 6457.

[50] J.A. Gaj, R. Planel, G. Fishman, Solid State Commun. 29 (1979) 435.

[51] V. Bindilatti, E. ter Haar, N.F. Oliveira, Y. Shapira, M.T. Liu, J. Appl. Phys. 85 (1999) 5950 .

[52] M.P.F. de Godoy, A. Mesquita, W. Avansi, P.P. Neves, V.A. Chitta, W.B. Ferraz M.A. Boselli, A.C.S. Sabioni, H.B. de Carvalho, J. Alloy. Compd. 555 (2013) 315.

[53] V.K. Sharma, N. Ojha, G.D. Varma, J. Phys. Chem. Solids 70 (2009) 941.

[54] W.W.M. Haynes, D.R. Lide, CRC Handbook of Chemistry and Physics: a Readyreference Book of Chemical and Physical Data, CRC, Boca Raton, Fla., London, 2011.

[55] C. Kittel, Introduction to Solid State Physics, eighth ed., John Wiley, Hoboken, N.J, 2005.

[56] J.B. Goodenough, Magnetism and the Chemical Bond, Interscience, New York; London, 1963.

[57] X. Zuo, S.D. Yoon, A. Yang, W.H. Duan, C. Vittoria, V.G. Harris, J. Appl. Phys. 105 (2009) 07C508.

[58] J.B. Yi, C.C. Lim, G.Z. Xing, H.M. Fan, L.H. Van, S.L. Huang, K.S. Yang, X.L. Huang, X.B. Qin, B.Y. Wang, T. Wu, L. Wang, H.T. Zhang, X.Y. Gao, T. Liu, A.T.S. Wee, Y.P. Feng, J. Ding, Phys. Rev. Lett. 104 (2010) 137201.

[59] G.Z. Xing, Y.H. Lu, Y.F. Tian, J.B. Yi, C.C. Lim, Y.F. Li, G.P. Li, D.D. Wang, B. Yao J. Ding, Y.P. Feng, T. Wu, AIP Adv. 1 (2011) 022152. 